\title{
Crystal growth of nanostructured zinc oxide nanorods from the seed layer
}

\author{
B.O. Adetoye ${ }^{1, *}$, A.B. Alabi ${ }^{1}$, T. Akomolafe ${ }^{1}$, P.B. Managutti $^{2}$, N. Coppede $^{3}$, \\ M. Villani ${ }^{3}$, D. CAlestani ${ }^{3}$, A. ZAPPETINi $^{3}$, C. MAurizio $^{3}$ \\ ${ }^{1}$ University of Ilorin, Ilorin, Kwara State, Nigeria \\ ${ }^{2}$ Solid State and Structural Chemistry Unit, Indian Institute of Science, Bengaluru 560012, India \\ ${ }^{3}$ Institute of Materials for Electronics and Magnetism, Parma, Italy
}

\begin{abstract}
One-dimensional (1D) zinc oxide ( $\mathrm{ZnO}$ ) nanostructures (nanorods) were synthesized on a glass slide and fluorine-doped tin oxide $\left(\mathrm{SnO}_{2} / \mathrm{F}\right.$ or FTO) coated glass (FTO/glass) by a wet chemical method. The structural, morphological and optical analyses of the as-deposited $\mathrm{ZnO}$ nanostructures were performed by X-ray diffractometry (XRD), scanning electron microscopy (SEM) and UV-Vis spectroscopy, respectively. The XRD results showed that the nanostructures as-deposited on the glass and the FTO/glass substrates were of $\mathrm{ZnO}$ wurtzite crystal structure, and the crystallite sizes estimated from the $\left(\begin{array}{llll}0 & 0 & 2\end{array}\right)$ planes were $60.832 \mathrm{~nm}$ and $64.876 \mathrm{~nm}$, respectively. The SEM images showed the growth of densely oriented $\mathrm{ZnO}$ nanorods with a hexagonal-faceted morphology. The UV-Vis absorption spectrum revealed high absorbance properties in the ultraviolet range and low absorbance properties in the visible range. The optical energy band gap of the $\mathrm{ZnO}$ nanostructure was estimated to be $3.87 \mathrm{eV}$ by the absorption spectrum fitting (ASF) method.
\end{abstract}

Keywords: zinc oxide; wet chemical method; nanostructure; absorption spectrum fitting

\section{Introduction}

The study of morphology, which includes shape, size and structure of a material, is especially important for nanostructured materials, because it determines their physical and chemical properties. It has been observed, that there is a strong correlation between the morphology of nanostructured materials and their properties, which totally deviate from the properties of their microscale and bulk forms [1-3]. One-dimensional (1D) nanostructures of metal oxides $\left(\mathrm{ZnO}, \mathrm{SnO}_{2}, \mathrm{TiO}_{2}\right)$ stand out as the most versatile materials among semiconductor nanostructures, due to their rich families, unique geometries with size confinement in two coordinates, diverse properties, and novel functionalities due to constrained movement of electrons and photons in one direction [4].

Zinc oxide $(\mathrm{ZnO})$, a II-VI binary semiconductor compound, with a wide direct band gap

*E-mail: banjiadetoye@gmail.com of $3.37 \mathrm{eV}$ and a large exciton binding energy of $60 \mathrm{meV}$ at room temperature [5], has one of the richest family of nanostructures among other materials in terms of diversified morphologies and properties [6]. It is a functional metal oxide semiconductor with unique electronic and optical properties, and ever-evolving applications and potential. Zinc oxide exhibits three crystal structures: cubic zinc blende, hexagonal wurtzite and cubic rocksalt, but under ambient conditions, zinc oxide exhibits hexagonal wurtzite structure, which is its thermodynamically stable form [7].

The easy formation in the synthesis of onedimensional (1D) $\mathrm{ZnO}$ nanostructures (nanorods (NRs) and nanowires (NWs)), their device applications in electronics [11], photonics and optoelectronics [12, 13], such as solar cells [8], sensors $[9,10]$, etc., and the correlation of their sizerelated electrical and optical properties have attracted a great deal of attention [14]. In addition, zinc oxide has been found to be biocompatible, biodegradable and bio-safe for medical 
and environmental applications $[15,16]$, due to its nontoxicity, and as such can be used without coating for biomedical applications.

Gas phase synthesis of $1 \mathrm{D} \mathrm{ZnO}$ nanostructures includes metal-organic chemical vapor deposition (MOCVD) [17], thermal evaporation [18], molecular beam epitaxy (MBE) [19], sputter deposition [20], vapor-liquid-solid (VLS) process [21], etc., which all require expensive and sophisticated equipment, high vacuum and high process temperatures. In comparison with the above mentioned techniques, the synthesis and growth of zinc oxide nanostructures by wet chemical deposition techniques such as chemical bath deposition (CBD) or hydrothermal synthesis [22], electrochemical deposition (ED) [23], etc., has favorable advantages which include low cost of setup, easy handling, operation under low temperature and pressure, compatibility with various substrates (except for $\mathrm{ED}$ which requires substrates with conductive surface), no requirements of catalyst-assisted process and possibility of employment in large-scale production.

In this work, zinc acetate dihydrate and hexamine (HMTA) solution were used in the synthesis of $\mathrm{ZnO}$ nanorods, with $\mathrm{ZnO}$ dispersion predeposited on the substrates as a seed layer. Though the solutions of zinc compounds (e.g. acetate, formate and chloride) containing HMTA were studied to yield nanorods [24], only few researchers [25] have actually used zinc acetate and HMTA solution to synthesize $\mathrm{ZnO}$ nanorods. In various works, zinc nitrate was the common and recurring zinc compound used for the synthesis of nanorods and nanowires [22, 24, 26-28], but in this work zinc acetate dihydrate was used which is a deviation from the norm. The synthesis of the $\mathrm{ZnO}$ nanorods follows the work of Vayssieres [22], with major modifications in the synthesis procedures.

\section{Experimental}

Glass slide and fluorine-doped tin oxide coated glass (FTO/glass) were used as substrates in the synthesis of the $\mathrm{ZnO}$ nanostructure (nanorods). Prior to the deposition, to make the substrates hydrophilic, they were washed with detergent and rinsed thoroughly with distilled water. The substrates were then immersed in a highly diluted $\mathrm{HCl}$ solution, and then rinsed with distilled water after which they were ultrasonically agitated in isopropyl alcohol (IPA) solution for $30 \mathrm{~min}$ followed by rinsing in distilled water and drying.

Zinc acetate dehydrate, $\mathrm{Zn}\left(\mathrm{CH}_{3} \mathrm{COO}\right)_{2} \cdot 2 \mathrm{H}_{2} \mathrm{O}$, and hexamethylenetetramine (HMTA), also called hexamine or methenamine, $\mathrm{C}_{6} \mathrm{H}_{12} \mathrm{~N}_{4}$, were used in the preparation of precursor solution for the synthesis of $\mathrm{ZnO}$ nanostructures. The cleaned substrates (FTO/glass and glass) were pre-deposited with $\mathrm{ZnO}$ seed layer using $\mathrm{ZnO}$ dispersion (a solution of $\mathrm{ZnO}$ nanoparticles) by spin coating and annealed in an oven for $1 \mathrm{~h}$ at $150{ }^{\circ} \mathrm{C}$. Equimolar aqueous solution of $10 \mathrm{mM}$ of $\mathrm{Zn}\left(\mathrm{CH}_{3} \mathrm{COO}\right)_{2} \cdot 2 \mathrm{H}_{2} \mathrm{O}$ and HMTA were prepared and stirred for $2 \mathrm{~h}$ on a magnetic stirrer. The substrates were placed in a beaker containing the precursor solution, covered with an aluminium foil and placed in the laboratory oven at the temperature of $90^{\circ} \mathrm{C}$. After $3 \mathrm{~h}$, the substrates were removed and washed with distilled water and dried in the oven at $60{ }^{\circ} \mathrm{C}$ for $1 \mathrm{~h}$, and then placed in a desiccator for characterization.

\section{Results and discussion}

The structural, morphological and optical properties of the as-deposited $\mathrm{ZnO}$ nanostructure were investigated by X-ray diffraction (XRD), scanning electron microscopy (SEM), and UV-Vis spectroscopy, respectively.

\subsection{XRD analysis}

The XRD patterns of the as-deposited $\mathrm{ZnO}$ nanostructures (nanorods) on glass and FTO/glass substrates investigated by X-ray diffractometry are shown in Fig. 1a and Fig. 1b, respectively, which reveal the crystalline structure of the as-deposited $\mathrm{ZnO}$ nanostructures. The peak intensities were measured in $2 \theta$ range of $30^{\circ}$ to $70^{\circ}$. Strong reflection from the $\left(\begin{array}{lll}0 & 0 & 2\end{array}\right)$ plane was recorded for $\mathrm{ZnO}$ nanostructures grown on the glass substrate, while strong reflections from the $\left(\begin{array}{lll}1 & 0 & 1\end{array}\right),\left(\begin{array}{lll}0 & 0 & 2\end{array}\right)$ and $\left(\begin{array}{lll}0 & 0 & 1\end{array}\right)$ planes were observed for the $\mathrm{ZnO}$ 
nanostructures grown on the FTO/glass substrate. The $\left(\begin{array}{lll}0 & 0 & 2\end{array}\right)$ plane of the $\mathrm{ZnO}$ nanostructures on the glass substrate appears to be the densest in comparison to the (llll $\left.\begin{array}{lll}1 & 0\end{array}\right),\left(\begin{array}{lll}0 & 0 & 2\end{array}\right)$ and $\left(\begin{array}{lll}0 & 0 & 1\end{array}\right)$ planes of the $\mathrm{ZnO}$ nanostructures grown on the FTO/glass substrate, which accounts for the strong reflection shown in Fig. 1a. The strong reflection from the $\left(\begin{array}{lll}0 & 0 & 2\end{array}\right)$ plane is also an indicator of vertical alignment of the $\mathrm{ZnO}$ nanorods, that is the growth along the c-axis normal to the substrate [29]. The vertical alignment of nanorods on the glass substrate can be attributed to the texture (smoothness), seed density and particularly the $\left(\begin{array}{lll}0 & 0 & 2\end{array}\right)$ orientation of the seed layer [30].
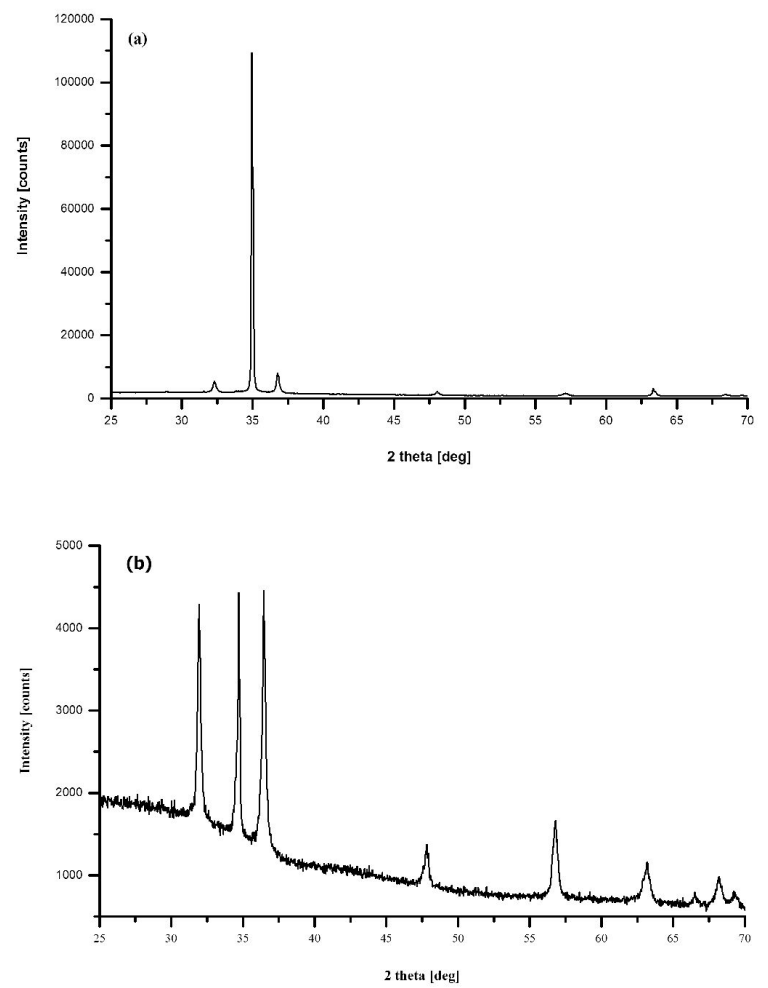

Fig. 1. XRD pattern of the as-deposited $\mathrm{ZnO}$ nanostructures grown on (a) glass, and (b) FTO/glass substrates.

The diffraction peaks of the XRD patterns were indexed to the hexagonal wurtzite structure of $\mathrm{ZnO}$ [31] and were found to be in agreement with JCPDS Card No. 036-1451. The structural parameters of the as-deposited $\mathrm{ZnO}$ nanostructures on the glass and FTO/glass substrates are shown in Table 1 and Table 2. The crystallite sizes were estimated from the $\left(\begin{array}{lll}0 & 0 & 2\end{array}\right)$ plane of each XRD pattern, and were found to be $60.832 \mathrm{~nm}$ and $64.876 \mathrm{~nm}$ for the glass substrate and FTO/glass substrate, respectively, using Scherrer formula:

$$
D=\frac{K \lambda}{\beta_{h k l} \cos \theta_{h k l}}
$$

where $\mathrm{D}$ is the crystallite size, $\mathrm{K}$ is Scherrer constant (0.94), $\lambda$ is wavelength of the monochromatic X-ray $(1.5406 \AA), \beta_{\mathrm{hk} 1}$ is full width at half maximum (FWHM), and $\theta_{\mathrm{hk} 1}$ is diffraction angle.

The interplanar/lattice spacing, $\mathrm{d}_{\mathrm{hkl}}$, of the crystallographic planes of the nanostructure was obtained using the Bragg equation, given by:

$$
\lambda=2 d_{h k l} \sin \theta_{h k l}
$$

The lattice parameters $\mathrm{a}$ and $\mathrm{c}$ of the $\mathrm{ZnO}$ nanostructure were calculated from the expression below:

$$
\frac{1}{d_{h k l}^{2}}=\frac{4}{3}\left(\frac{h^{2}+h k+k^{2}}{a^{2}}\right)+\frac{l^{2}}{c^{2}}
$$

The lattice constant, a, was obtained from equation 4 using the $\left(\begin{array}{lll}1 & 0 & 0\end{array}\right)$ plane and the lattice constant, c, was obtained from equation 5 using the $\left(\begin{array}{lll}0 & 0 & 2\end{array}\right)$ plane. These two equations ( 4 and 5) were derived from equation 3 :

$$
\begin{gathered}
a=\sqrt{\frac{4 h^{2} d_{100}^{2}}{3}} \\
c=\sqrt{l^{2} d_{002}^{2}}
\end{gathered}
$$

The calculated values of the lattice constants are in agreement with the standard values of JCPDS Card No. 36-1451 with lattice parameters of $\mathrm{a}=3.2493 \AA$ and $\mathrm{c}=5.1968 \AA$ [31].

The average microstrain $\epsilon$, and the average dislocation density $\rho$, were calculated from the following equations:

$$
\begin{gathered}
\varepsilon=\frac{\beta \cos \theta}{4} \\
\rho=\frac{15 \varepsilon}{a D}
\end{gathered}
$$


Table 1. Structure parameters of the $\mathrm{ZnO}$ nanorods (NRs) grown on glass substrate.

\begin{tabular}{lrccc}
\hline h k l plane & $2 \theta{ }^{\circ}{ }^{\circ}$ & FWHM, $\beta$ [rad] & Lattice spacing, $\mathrm{d}[\AA]$ & Crystallite size, D [nm] \\
\hline \hline$\left(\begin{array}{lll}1 & 0 & 0\end{array}\right)$ & 32.304 & 0.004049 & 2.769 & 37.234 \\
$\left(\begin{array}{lll}0 & 0 & 2\end{array}\right)$ & 34.956 & 0.002496 & 2.565 & 60.832 \\
$\left(\begin{array}{lll}1 & 0 & 1\end{array}\right)$ & 36.790 & 0.003683 & 2.441 & 41.442 \\
\hline
\end{tabular}

Table 2. Structural parameters of the $\mathrm{ZnO}$ nanorods (NRs) grown on FTO/glass substrate.

\begin{tabular}{|c|c|c|c|c|}
\hline h k l plane & $2 \theta\left[^{\circ}\right]$ & FWHM, $\beta$ [rad] & Lattice spacing, d [̊] & Crystallite size, D [nm] \\
\hline$\left(\begin{array}{lll}1 & 0 & 0\end{array}\right)$ & 31.946 & 0.003962 & 2.799 & 38.020 \\
\hline$\left(\begin{array}{lll}0 & 0 & 2\end{array}\right)$ & 34.721 & 0.002339 & 2.582 & 64.876 \\
\hline$\left(\begin{array}{lll}1 & 0 & 1\end{array}\right)$ & 36.474 & 0.003840 & 2.461 & 39.710 \\
\hline
\end{tabular}

\subsection{SEM analysis}

The morphological characterization of the asdeposited $\mathrm{ZnO}$ nanostructures was carried out by scanning electron microscopy (SEM).

Fig. 2 and Fig. 3 show the SEM images of the $\mathrm{ZnO}$ nanostructures (nanorods) at different magnifications.

The SEM images of the as-deposited $\mathrm{ZnO}$ nanostructures on the glass substrate show the growth of densely and highly oriented nanorods perpendicular to the substrate surface (Fig. 2). The images show the NRs covering the entire substrate surface and depict the hexagonal-faceted morphology.

The SEM images of the as-deposited $\mathrm{ZnO}$ nanostructure on the FTO/glass substrate (Fig. 3) show the growth of long, densely and randomly oriented nanorods on the substrate with hexagonalfaceted morphology. The nanorods are also seen to cover the entire surface of the substrate.

\subsection{Optical analysis}

The UV-Vis absorption spectrum of the asdeposited $\mathrm{ZnO}$ nanostructures, taken on unannealed sample, is shown in Fig. 4.

The absorption edge of the as-deposited $\mathrm{ZnO}$ nanostructure is at $335 \mathrm{~nm}$ which is lower than that of bulk $\mathrm{ZnO}$ (367 nm). The absorption edge wavelength indicates a blue shift in the absorption spectrum of the as-deposited $\mathrm{ZnO}$ nanostructure typical of unannealed samples [32].
The optical band gap, $E_{\mathrm{g}}$, was estimated by using the absorption spectrum fitting (ASF) method, which did not require the film thickness. The parameter $\lambda_{g}$ in equation 8 has been obtained from the linear extrapolation of the $\left(\frac{\operatorname{Abs}(\lambda)}{\lambda}\right)^{\frac{1}{m}}$ vs. $\frac{1}{\lambda}$ curve (Fig. 5), at $\left(\frac{\operatorname{Abs}(\lambda)}{\lambda}\right)^{\frac{1}{m}}=0$, whith $\mathrm{m}=\frac{1}{2}$ [33]:

$$
E_{g}=\frac{h c}{\lambda_{g}}
$$

where $\mathrm{h}$ is Planck constant, $\mathrm{c}$ is speed of light, $\lambda_{\mathrm{g}}$ is optical band gap wavelength.

From Fig. 5, at $\left(\frac{\operatorname{Abs}(\lambda)}{\lambda}\right)^{\frac{1}{m}}=0$, $\lambda_{g}=3.209 \times 10^{-7} \mathrm{~m}$.

Using equation 8 , the optical band gap, $\mathrm{E}_{\mathrm{g}}=3.87 \mathrm{eV}$, which is larger than that of bulk $\mathrm{ZnO}$ $(3.37 \mathrm{eV})$.

The widening of the optical band gap of the asdeposited $\mathrm{ZnO}$ nanostructures is a result obtained for the unannealed as-deposited sample used in the optical characterization. After annealing, a change from blue shift to red shift in the absorption spectrum of the $\mathrm{ZnO}$ nanostructure will occur, resulting in reduction of the optical band will [32].

\section{Conclusions}

In this work, one-dimensional zinc oxide nanostructures (nanorods) have been synthesized on two kinds of substrates (glass and FTO/glass) at $90{ }^{\circ} \mathrm{C}$ by wet chemical technique. XRD analysis revealed that the synthesized nanostructure is 


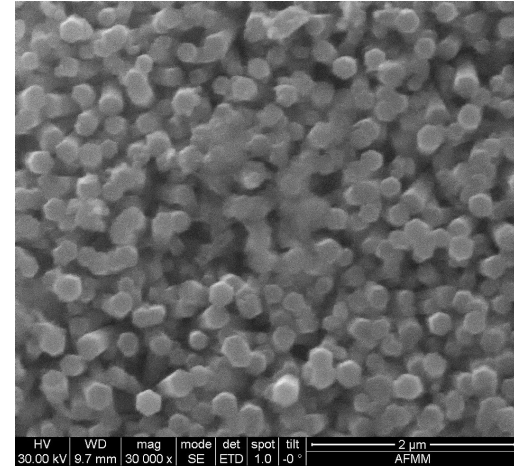

(a)

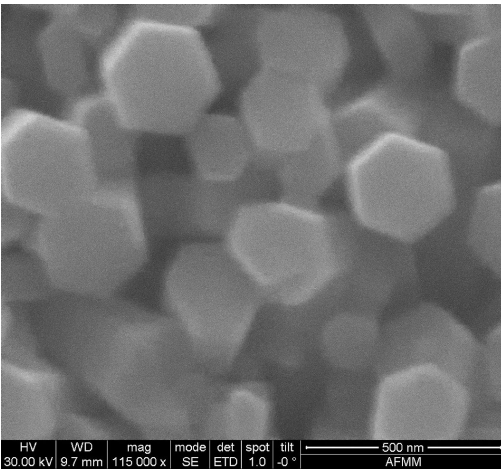

(b)

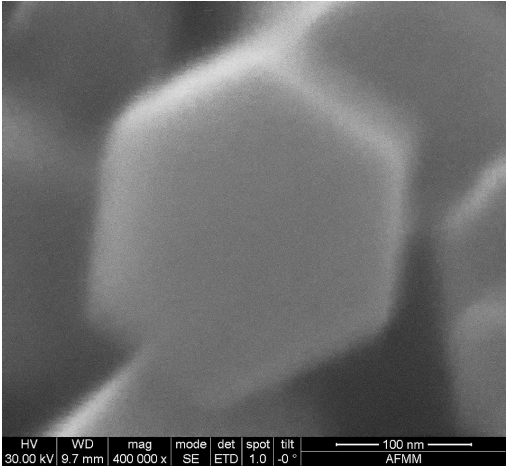

(c)

Fig. 2. The plain view SEM images of $\mathrm{ZnO}$ nanorods (NRs) grown on the glass substrate.

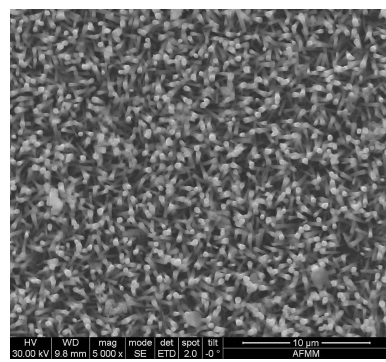

(a)

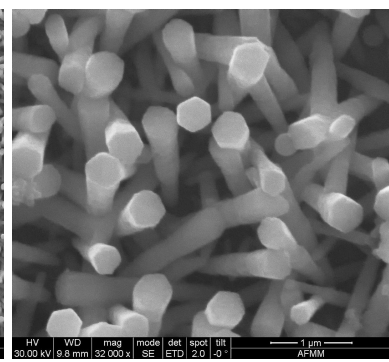

(b)

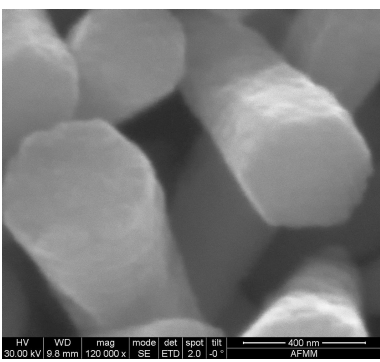

(c)

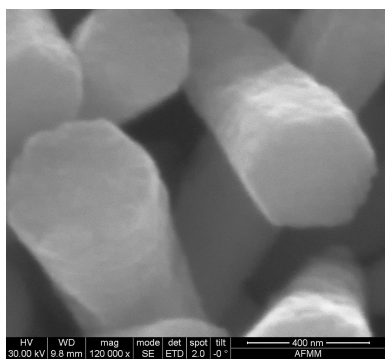

(d)

Fig. 3. The plain view SEM images of $\mathrm{ZnO}$ nanorods (NRs) grown on the $\mathrm{FTO} /$ glass substrate.

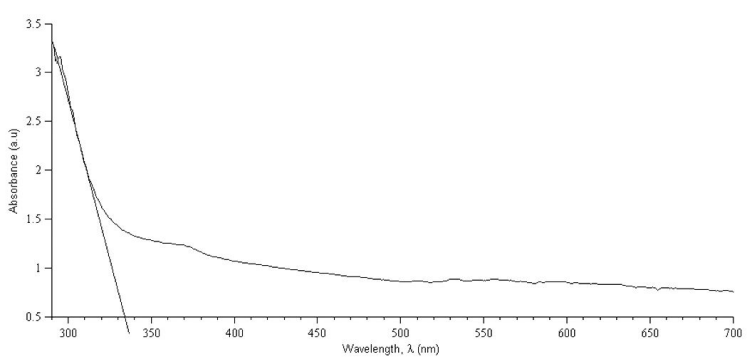

Fig. 4. The absorption spectrum of the as-deposited $\mathrm{ZnO}$ nanostructures on the glass substrate.

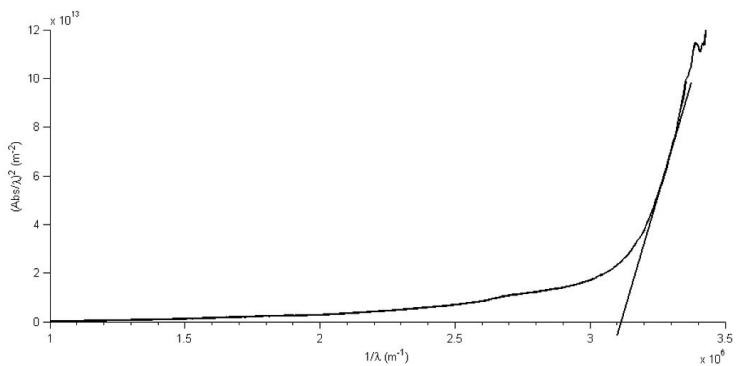

Fig. 5. The plot of absorption spectrum fitting (ASF).

There were also revealed high absorbance values in the ultraviolet wavelength range of $300 \mathrm{~nm}$ to $400 \mathrm{~nm}$ and low absorbance values in the visible wavelength range of $400 \mathrm{~nm}$ to $800 \mathrm{~nm}$, which is an intrinsic property of zinc oxide. The optical band gap, $\mathrm{E}_{\mathrm{g}}$, of the $\mathrm{ZnO}$ nanostructure estimated by the absorption spectrum fitting (ASF) method structures with an absorption edge of $335 \mathrm{~nm}$. was $3.87 \mathrm{eV}$. 
Table 3. Lattice constants/parameters of the as-deposited $\mathrm{ZnO}$ nanostructures.

\begin{tabular}{lccc}
\hline \multirow{2}{*}{ Lattice constants } & \multicolumn{2}{c}{ Substrates } & \multirow{2}{*}{ JCPDS standard value } \\
\cline { 2 - 3 } & Glass & FTO/glass & \\
\hline \hline $\mathrm{a}$ & $3.1974 \AA$ & $3.2323 \AA$ & $3.2493 \AA$ \\
$\mathrm{c}$ & $5.1295 \AA$ & $5.1632 \AA$ & $5.1968 \AA$ \\
\hline
\end{tabular}

Table 4. Summary of the structural parameters (average values) of the as-deposited ZnO nanostructures grown on glass and FTO/glass substrates.

\begin{tabular}{lccc}
\hline Substrates & Crystallite size, D [nm] & Microstrain, $\epsilon\left(\times 10^{-4}\right)$ & Dislocation density, $\rho\left(\times 10^{-4} \mathrm{~m}^{2}\right)$ \\
\hline \hline Glass & 46.503 & 8.137 & 8.910 \\
FTO/glass & 47.535 & 8.073 & 8.757 \\
\hline
\end{tabular}

\section{Acknowledgements}

The Institute of Materials for Electronics and Magnetism (IMEM), Parma, Italy. PBM thanks the DST-IRHPA Project (India) and the Indian Institute of Science for the project assistantship.

\section{References}

[1] Sanyal M.K., Datta A., Hazra S., Pure Appl. Chem., 74 (2002), 1553.

[2] Rao C.N.R., Cheetham A.K., J. Mater. Chem., 11 (2001), 2887.

[3] CAO G., Nanostructures and Nanomaterials - Synthesis, Properties, and Applications, Imperial College Press, London, 2004.

[4] Liao L., Duan X.F., More Recent Advances in OneDimensional Metal Oxide Nanostructures: Optical and Optoelectronics Application, in: Zhai T., Yao J. (Eds.), One-Dimensional Nanostructures: Principles and Application, $1^{\text {st }}$ ed., John Wiley \& Sons, Inc., 2013, p. 359.

[5] Thomas D.G., J. Phys. Chem. Solids, 15 (1960), 1.

[6] Wang Z.L., Mater. Today, 6 (2004), 26.

[7] Morkoç H., ÖzGür U., Zinc Oxide: Fundamentals, Materials and Device Technology, WILEY-VCH, Weinheim, 2009.

[8] Chou T.P., Zhang Q., Fryxell G.E, CaO G.Z., Adv. Mater., 19 (2007), 2588.

[9] WAn Q., Li Q.H., Chen Y.J., WANG T.H., HE X.L., Li J.P., Appl. Phys. Lett., 84 (2004), 3654.

[10] Hossain M.K., Ghosh S.C., Boontongkong Y., ThanACHAYANONT C., DUtTA J., JMNM, 23 (2005), 27.

[11] PARK W. I., Kim J.S., Yi G.-C., BAe M.H., LeE H.J., Appl. Phys. Lett., 85 (2004), 5052.

[12] Zhang X.M., LU M.Y., Zhang Y., Chen L.J., WANG Z.L., Adv. Mater., 21 (2009), 2767.

[13] Huang M.H., Mao S., Feick H., Yan H., Wu Y., KIND H., Weber E., Russo R., Yang P., Science, 292 (2001), 1897.

[14] Yi G.-C., Wang C., PARK W.I., Semicond. Sci. Tech., 20 (2005), S22.
[15] Zhou J., XU N., Wang Z.L., Adv. Mater., 18 (2006), 2432.

[16] Ali S.M.U, Nur O., Willander M., DanielsSON B., IEEE T. Nanotechnol., 8 (2009), 678.

[17] Lee W., Jeong M.C., Myoung J.M., Acta Mater., 52 (2004), 3949.

[18] DaI Z.R., PAN Z.W., WANG Z.L., Adv. Funct. Mater., 13 (2003), 9.

[19] Heo Y.W., Varadarajan V., Kaufman M., Kim K., Norton D.P., Ren F., Fleming P.H., Appl. Phys. Lett., 81 (2002), 3046.

[20] Chiou W., Wu W., Ting J., 12 (2003), 1841.

[21] Suh D.-I., Byeon C.C., LeE C.-L., Appl. Surf. Sci., 257 (2010), 1454.

[22] VAyssieres L., Adv. Mater., 15 (2003), 464.

[23] Yu L.G., Zhang G.M., Li S.Q., XI Z.H., Guo D.Z., J. Cryst. Growth, 299 (2007), 184.

[24] Greene L.E., Yuhas B.D., Law M., Zitoun D., YANG P., Inorg. Chem., 19 (2006), 7535.

[25] Wang M., Hahn S.H., KIM J.S., Hong S.H., KoO K.-K., KIM E.J., Mater. Lett., 62 (2008), 4532.

[26] Kim K.H., UtAshiro K., Abe Y., KaWAmura M., Materials, 4 (2014), 2522.

[27] Zheng Z., Lim Z.S., Peng Y., You L., Chen L., WANG J., Sci. Rep.-UK, 3 (2013), 2434.

[28] Foo K.L., Hashim U., Muhammad K., Voon C.H., Nanoscale Res. Lett., 9 (2014), 429.

[29] Kahraman S., Bayansal F., Çetinkara H.A., ÇAKMAK H.M., GÜder H.S., Mater. Chem. Phys., 134 (2012), 1036.

[30] Song J., Lim S., J. Phys. Chem. C, 111 (2007), 596.

[31] Powder Diffraction File 36-1451 for Hexagonal Zinc Oxide, JCPDS-International Center for Diffraction Data, 1997.

[32] TAn S.T., Chen B.J., Sun X.W., FAN W.J., J. Appl. Phys., 98 (2005), 013505.

[33] Ghobadi N., Nano Lett., 3 (2013), 2.

Received 2017-08-31 Accepted 2018-06-13 